\title{
Optimization of the terminal operating mode during the formation of a container block train
}

\author{
Marufdjan Rasulov", Masud Masharipov, and and Azizbek Ismatullaev \\ Tashkent State Transport University, Tashkent, Uzbekistan
}

\begin{abstract}
Currently, container shipping plays an important role in international logistics. Terminals handle containers between different modes of transport and are a key element in supply chains. The quality of transport services, in general, depends on the technical and technological parameters of container terminals. At the same time, the task is to optimize the operating mode of the container terminal to reduce logistics costs. This article presents the results of a study of the traffic flows of terminals adjacent to the Tashkent regional railway junction stations, obtained based on timing observations on the unloading of containers arriving at the terminal by road for shipment by container trains. Based on these observations, the regularities of the distribution of the probabilities of the arrival of containers at the terminal and the time of servicing vehicles by a gantry crane were established. With the help of the established patterns, the main indicators were selected that characterize the quality of the container terminal functioning. A mathematical model has been developed and an algorithm for finding the optimal operating mode of a container terminal when forming a container block train. As the results of calculations have shown, the volume of logistics costs for the operation of a container terminal depends on the type and quantity of used handling equipment and the number of supply of fitting wagons to loading and unloading routes.
\end{abstract}

\section{Introduction}

In practice, container terminals often increase the demand for servicing the loading or unloading of containers with limited capabilities of the system of handling equipment, that is, when the throughput of the loading and unloading section of road transport is not able to meet all incoming requirements in the form of container ships. At the same time, the task of achieving minimum logistics costs is to establish a rational ratio between the number of servicing devices and the intensity of incoming requests.

To date, in most of the studied terminals, when choosing to lift and transporting equipment, they proceed from mathematical formulas [1-4], [8-11]. This approach leads to downtime for vehicles, and in some cases, downtime of lifting and transport machines. In this connection, in this study, the task of applying the queuing theory is posed, which makes it possible to establish the optimal duration of servicing a container terminal.

*Corresponding author: tashiit_rektorat@mail.ru 


\section{Methods and Materials}

\subsection{Method of studying the arrival of containers at the terminal}

Simulation modeling has been used as a method for studying the flow of containers at the terminal. To study the characteristics of traffic flows, it is necessary to establish a distribution law for the receipt of container flows. At the same time, it is necessary to determine the following parameters by collecting and processing statistical data on the arrival of containers at the terminal by road:

- determination of the average number of containers arriving at the terminal during $t$ :

$$
m_{x}^{*}=\sum_{i=1}^{k} \bar{x}_{i} p_{i}^{*}
$$

where $\overline{x_{i}}$ is average value of a random variable in the $i$-th digit; $p_{i}^{*} \mathrm{~s}$ the frequency of hitting a random variable in the $i$-th digit; $i$ is digit number $(i=1,2, \ldots, k)$.

- determination of statistical variance characterizing the dispersion of a distribution series $D_{x}^{*}$ :

$$
D_{x}^{*}=\sum_{i=1}^{k} x_{i}^{2} p_{i}^{*}-\left(m_{x}^{*}\right)^{2}
$$

- determination of the statistical standard deviation characterizing the absolute deviation of the statistical series:

$$
\sigma_{x}^{*}=\sqrt{D_{x}^{*}}
$$

- to accept or refute the theoretical distribution, $\chi^{2}$ (chi-square):

$$
\chi^{2}=n \sum_{i=1}^{k} \frac{\left(p_{i}^{*}-p_{i}\right)^{2}}{p_{i}}
$$

where $p_{i}^{*}, p_{i}$ are respectively statistical and theoretical probabilities; $n$ is total number of observations; $i$ is digit number of statistical series $(i=1,2, \ldots, k)$.

- to assess the discrepancy between the statistical and theoretical distribution, the Romanovsky rule is applied:

$$
\frac{\chi^{2}-R}{\sqrt{2 R}} \leq 3
$$

where: $R$ is the number of degrees of freedom. It is determined by the number of bits $k$ minus the number of independent conditions $S$ imposed on the frequencies: $R=k-S$.

Below is the sequence for determining the mathematical expectation and the law of distribution of incoming traffic flow of vehicles with containers to the terminals of the Tashkent regional railway junction. 
The calculations to determine the mathematical expectation and the distribution law of incoming flows of containers to the terminal adjacent to the railway station " $\mathrm{T}$ " are shown in Table 1.

From table 1 shows that the mathematical expectation averages 96 containers per day. A hypothesis is put forward about the subordination of the probability of the arrival of containers to Poisson's law. Moreover, $P\left(\chi^{2}\right)=0.61$ at the significance level $\alpha=0.1$, $\chi_{0.1}^{2}=13.362$. Therefore, the inequality $\chi_{0.1}^{2}>\chi^{2}$ is satisfied, the hypothesis of the distribution to Poisson's law can be taken.

The histogram and hypothetical curve of the Poisson distribution density are shown in Figure 1.

Table 1. Probability distribution of containers arriving at the container terminal adjacent to station "T" (fragment of the table)

\begin{tabular}{|c|c|c|c|c|c|}
\hline $\begin{array}{c}\text { Number of } \\
\text { containers } \\
\text { arriving } x_{i}\end{array}$ & $\begin{array}{c}\text { Observed } \\
\text { frequency } \\
h_{i}\end{array}$ & $\begin{array}{c}\text { Statistical } \\
\text { frequency } \\
p_{i}^{*}\end{array}$ & $\begin{array}{c}\text { Mathematical } \\
\text { expectation } \\
p_{i}^{*} \cdot \overline{x_{i}}\end{array}$ & $\begin{array}{c}\text { Theoretical } \\
\text { frequency } \\
p_{i}\end{array}$ & $\chi^{2}$ \\
\hline $58-65$ & 0 & 0.0000 & 0.0000 & 0.0005 & 0.1851 \\
\hline $65-72$ & 3 & 0.0083 & 0.5677 & 0.0061 & 0.2838 \\
\hline $72-79$ & 10 & 0.0276 & 2.0856 & 0.0375 & 0.9382 \\
\hline $79-86$ & 44 & 0.1215 & 10.0276 & 0.1257 & 0.0487 \\
\hline $86-93$ & 76 & 0.2099 & 18.7901 & 0.2412 & 1.4639 \\
\hline $93-100$ & 106 & 0.2928 & 28.2569 & 0.2759 & 0.3762 \\
\hline $100-107$ & 84 & 0.2320 & 24.0166 & 0.1947 & 2.5987 \\
\hline $107-114$ & 29 & 0.0801 & 8.8522 & 0.0873 & 0.2130 \\
\hline $114-121$ & 9 & 0.0249 & 2.9213 & 0.0255 & 0.0062 \\
\hline $121-128$ & 1 & 0.0028 & 0.3439 & 0.0050 & 0.3580 \\
\hline Total & 362 & 1 & 95.8619 & 0.9993 & 6.4719 \\
\hline
\end{tabular}

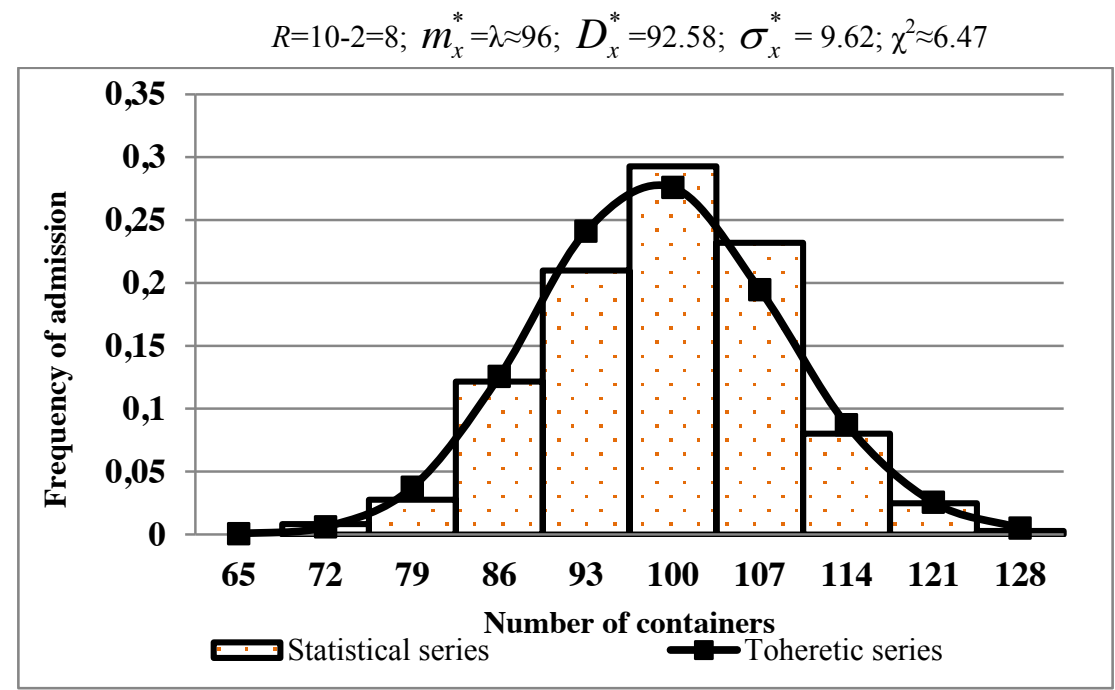

Fig.1. Histogram and hypothetical curve of the Poisson distribution density $\lambda=96$ con/day

The results of processing statistical data on the arrival of containers by road transport for dispatch by rail to the terminal adjacent to the station "Ch" are shown in Table 2. 
Table 2. Probability distribution of containers arriving at the container terminal adjacent to station "Ch" (fragment of the table)

\begin{tabular}{|c|c|c|c|c|c|}
\hline $\begin{array}{c}\text { Number of } \\
\text { containers } \\
\text { arriving } x_{i}\end{array}$ & $\begin{array}{c}\text { Observed } \\
\text { frequency } \\
h_{i}\end{array}$ & $\begin{array}{c}\text { Statistical } \\
\text { frequency } \\
p_{i}^{*}\end{array}$ & $\begin{array}{c}\text { Mathematical } \\
\text { expectation } \\
p_{i}^{*} \cdot \overline{x_{i}}\end{array}$ & $\begin{array}{c}\text { Theoretical } \\
\text { frequency } \\
p_{i}\end{array}$ & $\chi^{2}$ \\
\hline $80-86$ & 2 & 0.0056 & 0.4650 & 0.0090 & 0.4660 \\
\hline $86-92$ & 17 & 0.0476 & 4.2381 & 0.0351 & 1.5934 \\
\hline $92-98$ & 25 & 0.0700 & 6.6527 & 0.0927 & 1.9773 \\
\hline $98-104$ & 55 & 0.1541 & 15.5602 & 0.1702 & 0.5487 \\
\hline $104-110$ & 80 & 0.2241 & 23.9776 & 0.2220 & 0.0072 \\
\hline $110-116$ & 82 & 0.2297 & 25.9552 & 0.2092 & 0.7143 \\
\hline $116-122$ & 54 & 0.1513 & 18.0000 & 0.1449 & 0.0998 \\
\hline $122-128$ & 26 & 0.0728 & 9.1036 & 0.0748 & 0.0187 \\
\hline $128-134$ & 14 & 0.0392 & 5.1373 & 0.0292 & 1.2326 \\
\hline $134-140$ & 2 & 0.0056 & 0.7675 & 0.0087 & 0.3944 \\
\hline Total & 357 & 1 & 109.8571 & 0.9959 & 7.0524 \\
\hline
\end{tabular}

$$
R=10-2=8 ; m_{x}^{*}=\lambda \approx 110 \text { cont; } D_{x}^{*}=107.39 ; \sigma_{x}^{*}=10.36 ; \chi^{2} \approx 7.05
$$

A hypothesis has been put forward about the subordination of the probability of container arrival by road transport to the terminal to Poisson's law (see Table 2.). In this case, $P\left(\chi^{2}\right)=0.66$ at the significance level $\alpha=0.1, \chi_{0,1}^{2}=13.362$, which means that the inequality $\chi_{0.1}^{2}>\chi^{2}$ is fulfilled and the hypothesis of the distribution of Poisson's law can be taken.

Simultaneously with the observation of the arrival of containers at the terminal, it is necessary to consider the time distribution for servicing container flows.

\subsection{Results of servicing vehicles when unloading containers}

To determine the duration of the container servicing, time-based observations of the unloading process were carried out using a gantry crane (Figure 3), as well as a reach stacker (Figure 2). The figures show the results of observation with and without combining operations.

Figure 2 shows the results of timing observation of the unloading of containers at the terminal adjacent to the station "T." The given timing was made when the gantry crane was operating at the minimum distance between the vehicle and the stacking place. 


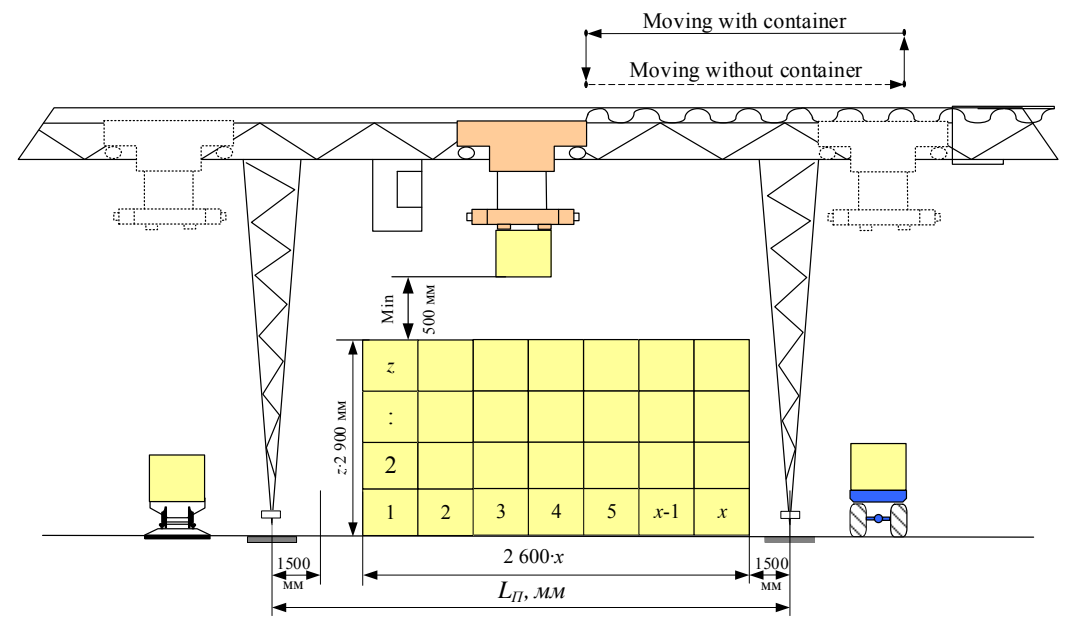

\begin{tabular}{|c|c|c|c|c|c|c|c|c|c|c|c|c|c|c|c|c|c|}
\hline \multirow{2}{*}{$\begin{array}{c}\text { Name of } \\
\text { operations }\end{array}$} & \multicolumn{17}{|c|}{ Time in seconds } \\
\hline & 10 & 20 & 30 & 40 & 50 & 60 & 70 & 80 & 90 & 100 & 0110 & 0120 & 0130 & 14015 & $50 \quad 160$ & & 70 \\
\hline & 20,0 & & & & & & & & & & & & & & & & \\
\hline Sling & $20,0[$ & & & & & & & & & & & & & & & & \\
\hline $\begin{array}{l}\text { Lifting the } \\
\text { container }\end{array}$ & & & & & & & & & & & & & & & & & \\
\hline $\begin{array}{l}\text { Telpher } \\
\text { movement }\end{array}$ & & & & & 15,0 & & & & & & & & & & & & \\
\hline Moving crane & & & & & & & 5,5 & & & & & & & & & & \\
\hline & & & & & & & & & 20,4 & & & & & & & & \\
\hline container & & & & & & & & & & & & & & & & & \\
\hline Removal & & & & & & & & & & 7, & & & & & & & \\
\hline $\begin{array}{l}\text { Raising the } \\
\text { spreader }\end{array}$ & & & & & & & & & & 10,0 & 19,0 & & & & & & \\
\hline $\begin{array}{c}\text { Telpher } \\
\text { movement }\end{array}$ & & & & & & & & & & & & & 17,0 & & & & \\
\hline Moving crane & & & & & & & & & & & & 23,4 & & 23,4 & & & \\
\hline Lowering slings & & & & & & & & & & & & & & & 6 & & \\
\hline Cycle without & & & & & & & & & 65,2 & & & & & & & 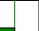 & \\
\hline alignment & & & & & & & & & & & & & & & & & \\
\hline Cycle taking into & & & & & & & 133. & & & & & & & & & & \\
\hline account & & & & & & & & & & & & & & & & & \\
\hline
\end{tabular}

Fig.2. Working cycle of gantry crane

Based on the collection and processing of statistical data, the values of the average service time of one container were determined:

$$
\tau=\sum_{i=1}^{k} \overline{\tau_{i}} p_{i}^{*}
$$

where: $\overline{\tau_{i}}$ is average service value of a random variable in the $i$-th bit.

Table 2 shows the data on determining the probability distribution of the service time of vehicles when using a gantry crane at the terminal adjacent to the station " $\mathrm{T}$ ".

Table 3. Distribution of probabilities of service time of vehicles by a gantry crane (fragment of the Table) 


\begin{tabular}{|c|c|c|c|c|c|}
\hline $\begin{array}{c}\text { Service time } \\
\tau\end{array}$ & $\begin{array}{c}\text { Observed } \\
\text { frequency } h_{i}\end{array}$ & $\begin{array}{c}\text { Statistical } \\
\text { frequency } \\
p_{i}^{*}\end{array}$ & $\begin{array}{c}\text { Mathematica } \\
1 \text { expectation } \\
p_{i}^{*} \cdot \overline{\tau_{i}}\end{array}$ & $\begin{array}{c}\text { Theoretical } \\
\text { frequency } \\
p_{i}\end{array}$ & $\chi^{2}$ \\
\hline $0-170$ & 485 & 0.3680 & 31.280 & 0.3791 & 0.4500 \\
\hline $170-340$ & 350 & 0.2656 & 67.728 & 0.2354 & 4.8906 \\
\hline $340-510$ & 170 & 0.1290 & 54.825 & 0.1462 & 2.7409 \\
\hline $510-680$ & 118 & 0.0896 & 53.312 & 0.0908 & 0.0333 \\
\hline $680-850$ & 72 & 0.0547 & 41.845 & 0.0564 & 0.1200 \\
\hline $850-1020$ & 44 & 0.0334 & 31.229 & 0.0350 & 0.1914 \\
\hline $1020-1190$ & 32 & 0.0243 & 26.851 & 0.0218 & 0.3103 \\
\hline $1190-1360$ & 24 & 0.0183 & 23.332 & 0.0135 & 2.0000 \\
\hline $1360-1530$ & 15 & 0.0114 & 16.473 & 0.0084 & 0.7500 \\
\hline $1530-1700$ & 8 & 0.0061 & 9.8515 & 0.0053 & 0.1428 \\
\hline Total & 1318 & 1.0004 & 356.72 & 0.9919 & 11.629 \\
\hline
\end{tabular}

$R=10-2=8 ; \tau \approx 5.95 \min ; D_{x}^{*}=108040.26 ; \sigma_{x}^{*}=328.69 ; \chi^{2} \approx 11.63$

A hypothesis is put forward about the subordination of the probability of servicing containers to the exponential distribution law-moreover, $P\left(\chi^{2}\right)=0.13$ at the significance level $\alpha=0.1, \chi_{0.1}^{2}=13.362$. Therefore, the inequality $\chi_{0.1}^{2}>\chi^{2}$ is satisfied. The hypothesis of the distribution of the probability of servicing containers according to the exponential law can be accepted. The histogram and hypothetical density curve of the exponential distribution law are shown in Figure 3.

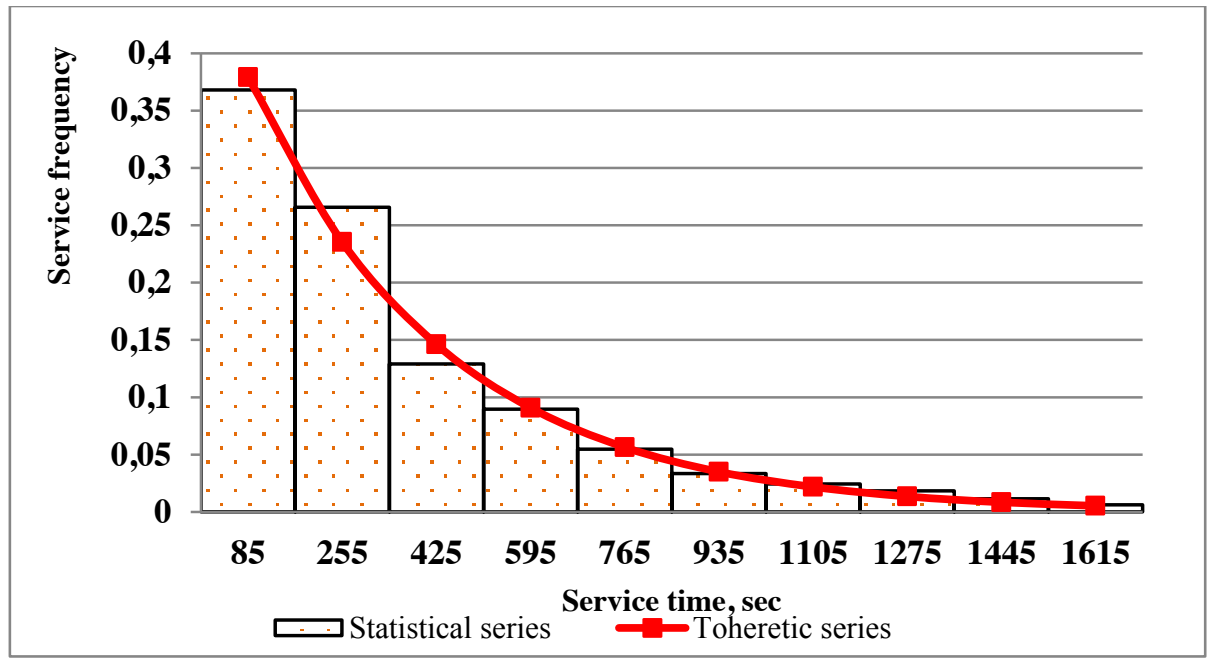

Fig.3. Histogram and hypothetical exponential distribution density curve at $\tau=357 \mathrm{sec}$.

Knowing the average values of $\lambda$ and $\tau$, it is possible to determine the values of the main indicators of the system under study. 


\section{Results and Discussion}

The quality of functioning of container terminals can be assessed by several indicators, the choice of which depends on the nature of the object's task. The main indicators and their relationship between them are shown in Table. 4.

Table 4. Main performance indicators of the container terminal adjacent to station "T" (in $\mathrm{z}=2 \mathrm{pcs}$., $\mathrm{T}=8$ hour.)

\begin{tabular}{|c|c|c|c|}
\hline № & Indicators & Formula & $\begin{array}{c}\text { Indicator } \\
\text { values }\end{array}$ \\
\hline 1 & System load & $\rho=\frac{\lambda}{\mu}$ & 600 \\
\hline 2 & $\begin{array}{c}\text { Average waiting time } \\
\text { for service }\end{array}$ & $\bar{\omega}=\left(\frac{\tau}{T}\right)^{2} \cdot \frac{N}{z\left(1-\frac{N \cdot \tau}{z \cdot T}\right)}$ & 0.02 \\
\hline 3 & Average queue length & $\bar{v}=\lambda \bar{\omega}$ & 1.92 \\
\hline 4 & $\begin{array}{c}\text { Average residence time } \\
\text { of requirements in the } \\
\text { system }\end{array}$ & $-\bar{u}=\tau+\bar{\omega}$ & 5.97 \\
\hline 5 & $\begin{array}{c}\text { Average number of } \\
\text { requests }\end{array}$ & $L=\lambda \bar{u}$ & 573 \\
\hline
\end{tabular}

where: $z$ is number of lifting and transport vehicles; $\mu$ is service intensity: $\mu=\frac{1}{\tau}$.

Based on table 3 with the initial parameters, it is not difficult to determine the rational values of these parameters. It is also possible, if necessary, to determine the total idle time of vehicles under container unloading or the total service time of $\mathrm{N}$ containers awaiting service during $T$.

Develop a mathematical model to find the optimal operating mode of a container terminal when forming a container blocks train. When servicing block trains, the main parameters of the container terminal are highlighted, which affect the organization of the block train. These include the number of feeds of fitting wagons to the loading and unloading track $\mathrm{x}$, the number of wagons in the feed $\mathrm{m}$, the number of hoisting-andtransport vehicles serving the block train $\mathrm{z}$, and the operating time of the container terminal $T$.

The problem of optimizing the parameters of a container terminal can be formulated as follows: for the given characteristics of the incoming flow of the requirement $\lambda$ and the type of service system $\tau$ of the block train, it is necessary to find such values of the variable parameters $\mathrm{x}, \mathrm{m}, \mathrm{z}, \mathrm{T}$ at which the optimization criteria would lead to a minimum:

$$
R^{*}(x, m, z, T)=\min _{x, m, z, T}
$$

in this case, the following constraints must be imposed on the variables $x, m, z, T$ : 


$$
\left.\begin{array}{c}
x_{\min } \leq x \leq \frac{N_{\text {sut }}}{\eta \cdot m} \\
\frac{N_{\text {sut }} \cdot t_{\text {sic }}}{60 \cdot T} \leq z \leq z_{\max } \\
m_{\min } \leq m \leq \frac{L_{j d}}{l_{v}} \\
\frac{N_{\text {per }}}{z \cdot N_{\text {hour }}} \leq T \leq 24
\end{array}\right\}
$$

where $N_{\text {sut }}$ is number of containers for shipment by block train, cont;

$\eta$ is number of twenty-foot containers on the k-th fitting platform, cont;

$m$ is number of $\mathrm{k}$ containers in the feed;

$L_{j d}$ is length of railway loading and unloading track, m;

$l_{6}$ is length of the k-th fitting platform, m;

$N_{\text {per }}$ is volume of cargo handling, cont.-operations per day;

$N_{\text {hour }}$ is technical performance of hoisting-and-transport machines, cont, hour.

$R_{I}$ is logistics costs associated with the downtime of fitting wagons during cargo operations. Upon the arrival of fitting wagons to the address of the container terminal:

$$
R_{1}=\frac{365 \cdot n^{2} \cdot S_{v a g}}{x \cdot z \cdot N_{h o u r}}
$$

where: $n$ is the number of fitting cars arriving in a container block train, wagons ;

$S_{6 a 2}$ is cost of 1 wagon-hour of downtime, million soums;

$R_{2}$ is logistics costs associated with the supply and cleaning of wagons at the loading and unloading track:

- when fitting cars arrive by block trains [5-7]:

$$
R_{2}=365 \cdot x \cdot t_{m} \cdot S_{l}
$$

- if the block train is divided into $x_{m}$ parts before feeding:

$$
R_{2}=365 \cdot m \cdot x_{m} \cdot S_{l}
$$

where $t_{m}$ is time for filing and cleaning, hour;

$S_{\Omega}$ is cost of 1 loco-hour of shunting work, million soums;

$R_{3}$ are expenses related to wages, mln. soums:

$$
R_{3}=365 \cdot T \cdot\left(z \cdot a+a_{k}\right)
$$

where: $a$ is wages of workers servicing the hoisting-and-transport machine, referred to 1 hour of its work, million soums;

$a_{k}$ is the cost of maintaining a container terminal related to 1 hour of its work, million soums);

$R_{4}$ are expenses related to the maintenance of the hoisting-and-transport vehicle, mln. soums: 


$$
R_{4}=z \cdot K_{z} \cdot(\alpha+\beta) \cdot 0.01
$$

where: $\alpha$ is annual depreciation charges for the complete restoration of the hoisting-andtransport machine;

$\beta$ is the annual depreciation deductions for the repair of the hoisting-and-transport machine;

$K_{z}$ is the cost of the hoisting-and-transport vehicle, million soums.

$R_{5}$ is the expenses related to the maintenance of the loading and unloading track, million soums:

-when the fitting cars arrive by block trains:

$$
R_{5}=m \cdot l_{B} \cdot K_{n} \cdot(\alpha+\beta) \cdot 0.01
$$

- if the block train is divided into $x_{m}$ parts before feeding:

$$
R_{5}=m \cdot x_{m} \cdot l_{B} \cdot K_{n} \cdot(\alpha+\beta) \cdot 0.01
$$

where: $\alpha$ is the annual depreciation deductions for the complete restoration of loading and unloading tracks;

$\beta$ is the annual depreciation deductions for the repair of loading and unloading tracks;

$K_{n}$ is the cost of 1 running meter of loading and unloading track, million soums.

$R_{6}$ are costs associated with waiting for vehicles to perform loading and unloading operations:

$$
R_{6}=365 \cdot \tau \cdot \lambda \cdot S_{m}
$$

where: $S_{m}$ is cost of 1 hour of vehicle downtime, million soums. As part of the study, an algorithm has been developed for finding the optimal operating mode of a container terminal when forming a container block train. Figure: 4. Algorithm for finding the optimal operating mode of the container terminal. The figure shows the dependence of the logistics costs of the container terminal adjacent to the station " $\mathrm{T}$ " for the following parameter values $m=14$ car/und; $z=2$ (gantry crane), pcs; $T=8$ hours.



Fig.5. Dependence of logistics costs of a container terminal when using gantry cranes 


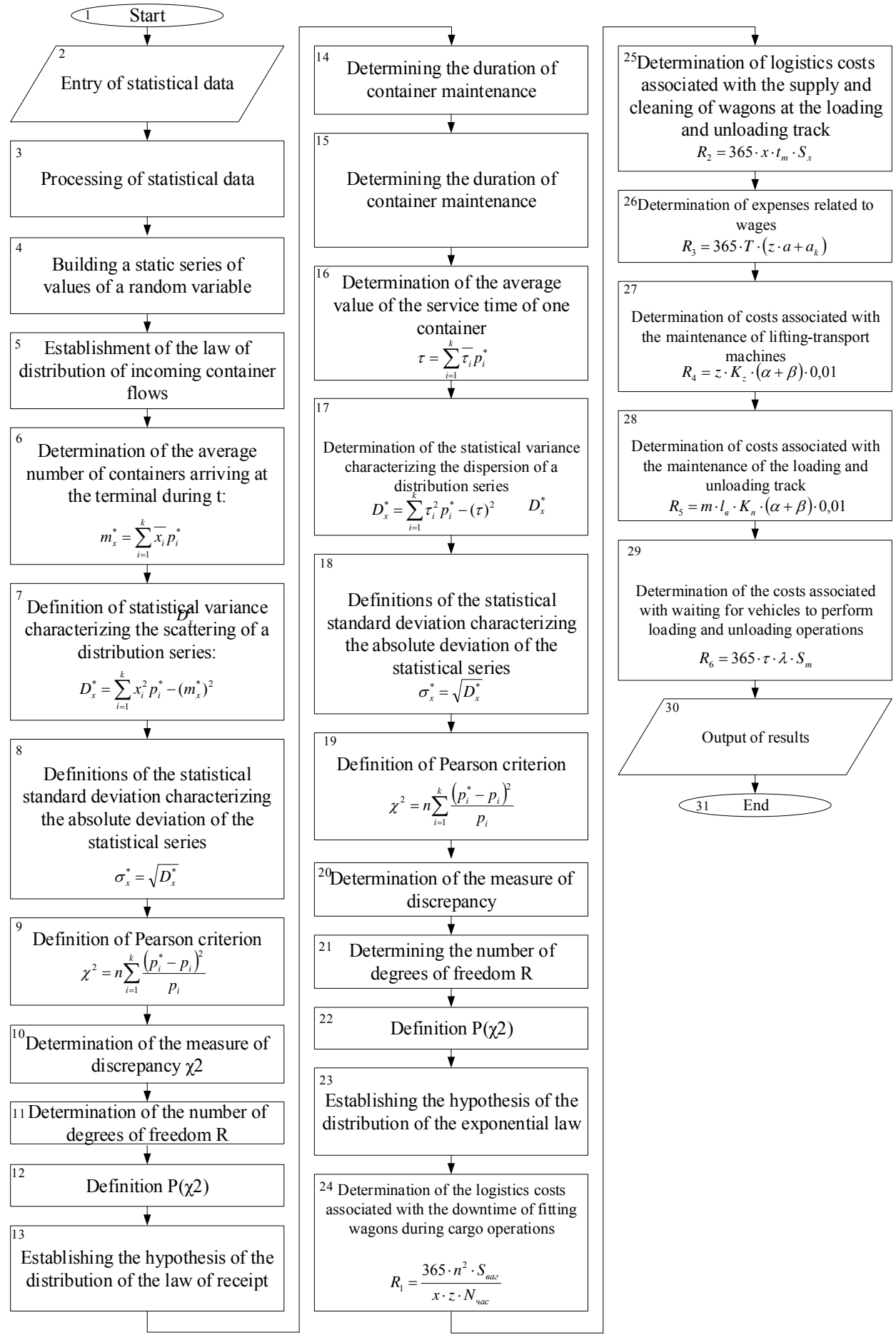

Fig.6. it can be seen that by changing the number of feeds, the optimal operating mode of the container terminal was determined when forming a container block train. 


\section{Conclusions}

Based on the research carried out, the following conclusions can be drawn:

1. The nature of the receipt of containers at the terminal by road has been determined. In most cases, the distribution obeys Poisson's law.

2. As a result of processing the statistical data of container unloading observations, it has been established that the service duration obeys the exponential distribution law.

3. The main values of the indicators of the container terminal have been determined. In the future, to improve or search for rational values of indicators, you can change the set parameters.

4. A mathematical model and an algorithm for finding the optimal operating mode of a container terminal for organizing a container block train have been developed.

5 . The results of modeling the operation of the container terminal showed that a change in feed affects the logistics costs of organizing block trains.

\section{Reference}

1. Voynov K. Stability of the laws for the distribution of the cumulative failures in railway transport, Transport problems, 3. (1). pp. 35-40. (2008)

2. Bakirov A.R. Investigation of operating modes of rolling stock by statistical methods, Science and technology of transport, (1). pp. 82-89. (2007).

3. Bakirov A.R. Research of operating modes of rolling stock by methods of the theory of probabilities and mathematical statistics, Transport of the Urals, 4 (15). pp. 20-24. (2007).

4. Bakirov A.R. Research of operating modes of rolling stock by methods of the theory of probabilities and mathematical statistics, Bulletin of the Moscow Automobile and Road Institute (State Technical University), 3 (10). pp. 27-32. (2007).

5. Ilesaliev D.I. Determination of the optimal values of the parameters of the loading and unloading area of packaged cargo, Bulletin of the Petersburg University of Railways, 3 (44). pp. 55-63. (2015)

6. Ilesaliev D.I. Determination of the optimal parameters of the loading and unloading area using mathematical methods, Transport: problems, ideas, prospects: Sat. tr. LXXV All-Russian. scientific and technical conf. students, graduate students and young scientists. - SPb .: FGBOU VPO PGUPS, pp 227-233. (2015).

7. Korovyakovsky E.K. Regularities of transport service of cotton fiber cargo traffic, Intelligent systems in transport: a collection of abstracts of the VI international scientific and practical conference dedicated to the 85th anniversary of the Faculty of Transportation Management. - SPb .: FGBOU VO PGUPS, pp. 47-48. (2014).

8. Kochneva D.I. Modeling of streaming processes at a container terminal, Bulletin of the Ural State University of Railways, 2. (22). pp. 53-60. (2014)

9. Kudryavtsev V.A, Zhukovskiy E.M, Efimenko Yu. I., Romanov A.P, Semyonov V.M, Application of mathematical methods in operational calculations on railway transport, 1.L LIIZHT p. 65. (1977).

10. Malykhin M.O. Justification of the initial data when modeling the export of containers from the port to the rear terminal using the Block-Train technology, M.O. Malykhin, A.V. Kirichenko, Bulletin of the State University of Marine and River Fleet named after Admiral S.O. Makarova. 4. (32). pp. 22-30. (2015).

11. Mironyuk V.P. Processing of the distribution of time for servicing vehicles when handling containers, Engineering Bulletin of the Don, 4. (18). pp. 568-572. (2011). 
12. Malikov O.B Increase in processing capacity of the container terminal. Vestnik gosudarstvennogo morskogo universiteta im. admirala F.F. Ushakova, 3, (8), pp. 3641. (2014).

13. Daurenbek I. Ilesaliev, Shahboz R. Abduvakhitov,Azizbek F. Ismatullaev, Shakhobiddin G. Makhmatkulov. Research of the main storage area of the container terminal. International Journal of Engineering and Advanced Technology (IJEAT), 9 (1), pp 4625-4630. (2019).

14. Ilesaliev, I.I., Makhmatkulov, S.G., Abduvakhitov, S.R. Peculiarities of container terminal functioning in delivery chains. IOP ConferenceSeries: Materials Science and Engineering, 918 (1), 012043. (2020).

15. D.I.Ilesaliev, Sh.R.Abduvakhitov, G.R.Ibragimova, F.K.Azimov Razrabotka klassifikatsii konteynernykh terminalov po urovnyu razvitiya. Transport sholkovogo puti, 3, (2020)

16. Luo J, Wu Y, Halldorsson A, Song X, Storage and stacking logistics problems in container terminals. OR Insight (24): pp 256-275. (2011)

17. Stahlbock, R. and Voss, S. Operations research at container terminals: a literature update. OR Spectrum, 30 (1) pp 1-52. (2008).

18. Steenken D, Voß S, Stahlbock R, Container terminal operations and operations research - a classification and literature review. OR Spectrum 26: pp 3-49. (2004).

19. Chen, L., Lu Z. The storage location assignment problem for outbound containers in a maritime terminal, International Journal of Production Economics, 135, pp 73-80, (2012)

20. Cristina Serban, Doina Carp A Genetic Algorithm for Solving a Container Storage Problem Using a Residence Time Strategy. Studies in Informatics and Control, 26, (1), March 2017. (2017).

21. Dekker R, Voogd P, Van Asperen E. Advanced methods for container stacking. OR Spectrum 2006; 28 (4), 563-86. (2006)

22. Galle, V., Barnhart, C., and Jaillet, P. A new binary formulation of the restricted container relocation problem based on a binary encoding of configurations. European Journal of Operational Research, 267 pp 467-477. (2018).

23. Khadjimukhametova M.A., Merganov A.M. Method for calculating the injection effect to create air circulation inside containers. International Journal of Innovative Technology and Exploring Engineering, 9 (1), 3222-3224. doi:10.35940/ijitee.A9160.119119. (2019).

24. Ilesaliev, D., \& Avaz, M. Research package efficiency general cargo. International Journal of Engineering and Advanced Technology, 9 (1), pp 6880-6884. doi:10.35940/ijeat.A2992.109119. (2019). 